\title{
RISK ASSESSMENT FOR THE CONSUMPTION OF FISH WITH ELEVATED SELENIUM LEVELS
}

\section{Craig Dalton and Phillip Bird} Hunter Public Health Unit

This article describes an application of risk assessment for the consumption of fish with elevated selenium levels, from Lake Macquarie, which is in the Hunter region of New South Wales.

\section{BACKGROUNDTOTHE INITIAL STUDY OF SEAFOOD IN LAKE MACQUARIE}

Concern about possible health risks associated with heavy metal contamination of seafood in Lake Macquarie was highlighted, following the release of a study by Boyd Roberts in September $1995 .{ }^{1}$ The study reported elevated concentrations of selenium (Se) in fish caught near power stations in the southern part of the lake in 1993. These results were corroborated by studies commissioned by the operator of the power station, Pacific Power. Because all of these studies focused on areas of the lake in the vicinity of industry, it was decided that a more broadly-based study should be commissioned to look at a range of heavy metals in fish caught at multiple sites that would be more representative of the entire lake.

A steering committee comprising representatives of the Hunter Public Health Unit, the NSW Environment Protection Authority (EPA), NSW Fisheries, Pacific Power, Delta Power, Pasminco smelter, Lake Macquarie Council, commercial fishermen, recreational fishermen, and consultants from the University of Newcastle, developed a protocol for sampling fish from 10 separate sites in the lake, including some sites that were not in the immediate vicinity of any heavy industry.

Five different species of fish were sampled in each site in three different weight categories. Five fish in each speciesweight category were to be caught and tested under the protocol. The five fish in each category constituted a 'batch'. The species sampled included Sea Mullet, Black and Yellow Fin Bream, Dusky Flathead, Trumpeter Whiting, and Luderick. The flesh from each batch was homogenised and tested for selenium, copper, lead, arsenic, cadmium, zinc, and mercury. Analysis of the data revealed that selenium was elevated in a wide range of fish caught in many sites throughout the lake.

A risk assessment for consumption of fish from Lake Macquarie was conducted, to determine the safe level of fish consumption for people regularly consuming fish from the lake over a lifetime. This risk assessment used a maximum safe intake of selenium of $0.005 \mathrm{mg} / \mathrm{kg} / \mathrm{day}$.

\section{METHODS}

To determine the maximum allowable intake of selenium, we reviewed recommendations from selected agencies around the world: the Agency for Toxic Substances and Disease Registry (ATSDR), Centers for Disease Control and Prevention, US Public Health Service; ${ }^{2}$ the United States Environmental Protection Agency (US EPA) ${ }^{3}$ the World Health Organization (WHO) $;^{4}$ and the National Health and Medical Research Council (NHMRC), Australia (Table 1). ${ }^{5}$

The ATSDR and US EPA levels are based on a 'no observed adverse effect level' (NOAEL) of an intake of $0.015 \mathrm{mg}$ $\mathrm{Se} / \mathrm{kg} /$ day or $0.85 \mathrm{mg} \mathrm{Se} /$ day, based on Chinese subjects who had an average weight of $55 \mathrm{~kg}$, established in a study by Yang et al. ${ }^{6}$ Both the ATSDR and the US EPA divided the NOAEL by an uncertainty factor of three to allow for sensitive individuals, giving a maximum safe level of intake of $0.005 \mathrm{mg} \mathrm{Se} / \mathrm{kg} /$ day. In 1994, an Expert Consultation between the Food and Agriculture Organization of the United Nations and the WHO,

\section{TABLE 1}

MAXIMUM ALLOWABLE INTAKE OF SELENIUM RECOMMENDED BY SELECTED INTERNATIONAL AGENCIES

\begin{tabular}{|c|c|c|}
\hline Agency & Criteria & $\begin{array}{l}\text { Upper estimated safe level } \\
\text { chronic oral ingestion }\end{array}$ \\
\hline ATSDR $^{*}$ & Minimal risk level & $0.005 \mathrm{mg} / \mathrm{kg} / \mathrm{day}$ \\
\hline US EPA ${ }^{\dagger}$ & Reference dose & $0.005 \mathrm{mg} / \mathrm{kg} / \mathrm{day}$ \\
\hline $\mathrm{WHO} * *$ & Maximal daily safe intake & $0.4 \mathrm{mg} /$ day for adult of $55 \mathrm{~kg}(0.007 \mathrm{mg} / \mathrm{kg} / \mathrm{day})$ \\
\hline NHMRC $\ddagger$ & Adverse effect level & $0.4-0.6 \mathrm{mg} / \mathrm{day}$ for adult $(0.006-0.009 \mathrm{mg} / \mathrm{kg} / \mathrm{day})$ \\
\hline \multicolumn{3}{|c|}{ * Agency for Toxic Substances and Disease Registry, Centers for Disease Control and Prevention, US Public Health Service. ${ }^{2}$} \\
\hline \multicolumn{3}{|c|}{$\dagger$ United States Environmental Protection Agency. ${ }^{3}$} \\
\hline \multicolumn{3}{|c|}{ ** World Health Organization. ${ }^{4}$} \\
\hline \multicolumn{3}{|c|}{$\ddagger \quad$ National Health and Medical Research Council, Australia. ${ }^{5}$} \\
\hline
\end{tabular}


accepted the NOAEL established by Yang et al. and their suggestion that a maximal safe dietary intake of selenium be set at $0.4 \mathrm{mg}$ per day based on an uncertainty factor of two. For a $55 \mathrm{~kg}$ adult, this equals $0.007 \mathrm{mg} / \mathrm{kg} / \mathrm{day}$.

The end points of interest in the Yang et al. study were toenail changes consistent with selenosis. Although this may appear to be a minor health event, it is evidence of disordered function at the cellular level. There may be other adverse affects that are not clinically observable. There is evidence of effects on glutathione peroxidase activity, with selenium intake around $0.85 \mathrm{mg}$ per day, again suggesting some alteration of function at the cellular level.
In the study by Yang et al., ${ }^{6}$ which formed the basis of the NOAEL, the actual proportion of ingested selenium that was absorbed was not known. In the Lake Macquarie risk assessment, no adjustments were made for absorption as it was assumed that the same proportion of selenium was absorbed from the fish as was absorbed from the diet of the subjects in the Yang study. The NOAEL is based on the level of selenium ingested, not the level absorbed. However, there may be differences in the level of absorption of selenium from Lake Macquarie fish that could bias the assessment in either direction. Absorption from some fish has been shown to be as low as 20 per cent in animal models; however, it is not known how this correlates with absorption by humans.

\section{TABLE 2}

CALCULATION FOR MAXIMUM SAFE INTAKE OF FISH FROM LAKE MACQUARIE FOR 70 KG ADULT, VALUE OF VARIABLES USED IN RISK ASSESSMENT

\begin{tabular}{|c|c|c|c|}
\hline \multicolumn{2}{|l|}{ Variable } & Value & Source \\
\hline \multicolumn{2}{|c|}{ Mean selenium level in fish from Lake } & $1.2 \mathrm{mg} / \mathrm{kg}$ & Lake Macquarie Seafood study 1996 \\
\hline \multicolumn{2}{|c|}{ Mean intake of fish/day for adult $=11 \mathrm{~g} /$ day } & $77 \mathrm{~g} /$ week & National Dietary Survey, 1983 \\
\hline \multicolumn{2}{|c|}{ Mean selenium levels in fish in Australia } & $0.6317 \mathrm{mg} / \mathrm{kg}$ & Australian Market Basket Survey, 1994 \\
\hline \multicolumn{2}{|l|}{ Adult weight } & $70 \mathrm{~kg}$ & \\
\hline \multicolumn{2}{|c|}{$\begin{array}{l}\text { Maximal safe weekly intake of selenium } \\
=0.005 \mathrm{mg} / \mathrm{kg} / \mathrm{day}\end{array}$} & $2.45 \mathrm{mg} /$ week for $70 \mathrm{~kg}$ adult & US EPA,†ATSDR, ${ }^{*}$ \\
\hline \multicolumn{2}{|c|}{$\begin{array}{l}\text { Total average weekly dietary intake of } \\
\text { selenium per kg body mass, Australian male. }\end{array}$} & $0.0125 \mathrm{mg} / \mathrm{kg} /$ week & Australian Market Basket Survey, 1994 \\
\hline \multicolumn{2}{|c|}{$\begin{array}{l}\text { Total average weekly dietary intake of } \\
\text { selenium for a } 70 \mathrm{~kg} \text { Australian adult male }\end{array}$} & $0.0125 \times 70=0.875 \mathrm{mg} /$ week & Calculation from above figure \\
\hline \multicolumn{2}{|c|}{$\begin{array}{l}\text { Toxic threshold from lowest -observed- } \\
\text { adverse-effect-level.(LOAEL) }\end{array}$} & $0.016 \mathrm{mg} / \mathrm{kg} / \mathrm{day}$ & Yang et al. ${ }^{6}$ \\
\hline \multicolumn{2}{|l|}{ Toxic threshold for $70 \mathrm{~kg}$ adult per week } & $\begin{array}{l}0.016 \mathrm{mg} / \mathrm{kg} / \text { day } \times 70 \mathrm{~kg} \times 7 \text { days } \\
=7.84 \mathrm{mg} / \text { week }\end{array}$ & Calculation from above figure \\
\hline \multicolumn{4}{|c|}{$\begin{array}{l}\text { * Agency for Toxic Substances and Disease Regis } \\
\dagger \text { United States Environmental Protection Agency }\end{array}$} \\
\hline Background intake of selenium & \multicolumn{3}{|c|}{$=$ total intake - fish contribution } \\
\hline \multirow[t]{3}{*}{ Fish contribution } & \multicolumn{3}{|c|}{$=$ mean intake/week $\mathrm{x}$ mean selenium in Australian fish } \\
\hline & \multicolumn{2}{|c|}{1000} & \\
\hline & \multicolumn{3}{|c|}{$=0.0486 \mathrm{mg} /$ week for $70 \mathrm{~kg}$ adult } \\
\hline Background intake (excluding fish) & \multicolumn{3}{|c|}{$=0.875-0.0486=0.8264 \mathrm{mg} /$ week } \\
\hline \multicolumn{4}{|c|}{ Toxic threshold of intake of fish from Lake } \\
\hline \multicolumn{4}{|c|}{$=\frac{\text { Weekly intake at LOAEL for } 70 \mathrm{~kg} \text { adult }- \text { Background intake }}{\text { Mean selenium level in fish in Lake }}$} \\
\hline \multicolumn{4}{|c|}{$=\frac{7.84 \mathrm{mg}-0.8264 \mathrm{mg}}{1.2 \mathrm{mg} / \mathrm{kg}}$} \\
\hline \multicolumn{4}{|c|}{$=5.85 \mathrm{~kg}$} \\
\hline \multicolumn{4}{|c|}{ Allowable intake of fish from Lake } \\
\hline \multicolumn{4}{|c|}{$=\frac{\text { Maximal safe weekly intake }- \text { Background intake }}{\text { Mean selenium level in fish from Lake }}$} \\
\hline \multicolumn{4}{|c|}{$=2.45 \mathrm{mg}-0.8264 \mathrm{mg}$} \\
\hline \multicolumn{4}{|c|}{$=1.35 \mathrm{~kg} /$ week } \\
\hline
\end{tabular}


Another study that supports the safety, and likely conservative nature, of an intake of $0.005 \mathrm{mg} / \mathrm{kg}$ /day was conducted in an area of the United States with high selenium levels in soil and diet. ${ }^{7}$ It revealed no morbidity in 76 subjects with a mean daily selenium intake of 0.239 $\mathrm{mg}$, including 12 subjects with an intake in excess of 0.4 $\mathrm{mg} /$ day and one subject with an intake of $0.724 \mathrm{mg} /$ day.

\section{RESULTS}

The findings of this risk assessment suggest that a $70 \mathrm{~kg}$ adult would be able to consume $1.35 \mathrm{~kg}$ of Lake Macquarie fish per week if they had the mean dietary intake of selenium from other sources found in the 1994 Australia New Zealand Food Authority's Market Basket Survey (Table 2).

\section{DISCUSSION}

The risk assessment based on conservative but reasonable assumptions allows an intake of fish from Lake Macquarie of $1.35 \mathrm{~kg}$, which is more than 17 times the mean national weekly intake of 77 grams. This level of intake is only likely to occur among people and their families who fish commercially or recreationally from Lake Macquarie.

When this risk assessment was conducted the standard for selenium in food in Australia was $1 \mathrm{mg} / \mathrm{kg}$; however, this was under review as it was not based on health risk assessment. In the interim we thought it was appropriate to develop dietary guidelines for consumers of Lake Macquarie fish based on health risk assessment. This risk assessment allows a $70 \mathrm{~kg}$ adult to consume $1.35 \mathrm{~kg}$ of fish per week continuously for a lifetime. This allows for much greater than $1.35 \mathrm{~kg}$ of fish in any given week as long as the average is below $1.35 \mathrm{~kg}$. It must be emphasised that this is the upper limit of safe intake, not the threshold for toxicity. The conservative assumptions, and the threefold safety factor used in deriving a safe upper limit intake of $0.005 \mathrm{mg} / \mathrm{kg}$, should ensure that the threshold for toxicity in the average person is much higher than this.

No evidence for increased sensitivity to selenium in children or pregnant women exists so their intake of Lake Macquarie seafood should be based on the same risk assessment. ${ }^{2,6}$ Smaller adults and children should consume fish in proportion to their weight; that is, a $35 \mathrm{~kg}$ child should be allowed 675 grams of fish, or half of the $1.35 \mathrm{~kg}$ allowed a $70 \mathrm{~kg}$ adult.
There was a limited number of Blue Swimmer Crabs, and no prawns were caught for this study. The mean selenium levels in the Blues Swimmer Crabs were similar to that in fish with fins, and in prawns, which have been found to have similar levels of selenium to fish with fins caught in the same location in other studies. Therefore, it would be reasonable to allow a total intake of $1.35 \mathrm{~kg}$ for all fish, crabs, and prawns per week from Lake Macquarie for a 70 $\mathrm{kg}$ adult until further data is available.

Because selenium and other metals may accumulate in the internal organs of fish, ${ }^{1}$ consumers should be discouraged from consuming internal organs or using whole fish as stock.

Fact sheets informing fisherman of the outcome of the risk assessment, and the advice to eat only $1.35 \mathrm{~kg}$ per week, were distributed through fishing cooperatives, bait and tackle shops, and through public meetings; a press release and media conference received widespread media coverage. While not formally assessed the public appeared to accept the risk assessment and no groups disputed the process or the findings. Since the study, commercial fishing has been banned in Lake Macquarie, due to depletion of fish stocks and not for reasons of public health.

\section{REFERENCES}

1. Roberts B. The accumulation and distribution of selenium in fish from Lake Macquarie, NSW. Canberra: Faculty of Applied Science, University of Canberra, 1994 (Master's thesis).

2. Agency for Toxic Substances and Disease Registry. Toxicological profile for selenium. Atlanta: United States Department of Health and Human Services, Public Health Service, 1996.

3. Poirer K.A. Summary of the derivation of the reference dose for selenium. Mertz W, Abernathy CO, Olin SS (editors). Risk assessment of essential elements. Washington DC: ILSI Press, 1994; 57-165.

4. WHO. Chapter 6. Selenium. Trace elements in human nutrition and health. Geneva: World Health Organization, 1996.

5. NHMRC. Recommended Dietary Intakes for use in Australia. Canberra: National Health and Medical Research Council, Australian Government Publishing Service, 1991.

6. Yang G, Yin R, Zhou L et al. Studies of safe maximal daily dietary Se-intake in a seleniferous area in China. Part II: Relation between Se-intake and manifestation of clinical signs and certain biochemical alterations in blood and urine. J Trace Elem Electrolytes Health Dis 1989; 3: 123-30.

7. Longnecker MP, Taylor PR, Levander OA, et al. Selenium in diet, blood and toenails in relation to human health in a seleniferous area. Am J Clin Nutr 1991; 53: 12988-94. Wr 